\title{
PENGARUH FAKTOR KEBERSIHAN, PENERANGAN DAN PERALATAN PRODUKSI TERHADAP PRODUKTIVITAS KARYAWAN PADA CV SINAR BADJA ELECTRIC DI SURABAYA
}

\author{
Yunni Rusmawati DJ \\ Prodi Manajemen, Fakultas Ekonomi, Universitas Islam Lamongan \\ Jl. Veteran No.53A Lamongan \\ Telp. ( 0322 ) 324706, Faks. ( 0322 ) 324706 \\ Email :jpim@unisla.ac.id
}

\begin{abstract}
ABSTRAK
Penelitian ini bertujuan untuk mengetahui faktor kebersihan, penerangan dan peralatan produksi terhadap produktivitas karyawan pada CV Sinar Baja Electric. Penelitian ini menggunakan metode kuantitatif deskriptif, yaitu kebersihan (X1), penerangan (X2) peralatan produksi (X3) dan produktivitas karyawan $(Y)$. Dalam penelitian ini menggunakan data sebanyak 30 responden dari karyawan CV Sinar Badja Elektric di Surabaya dengan menggunakan alat analisis uji regresi berganda, uji korelasi berganda, uji $t$ dan uji F. Hasil analisis menunjukkan uji regresi berganda diperoleh persamaan $Y=5,792+0,179 X 1+$ 0,238X2 + 0,170X3 nilai paling dominan adalah penerangan (X2) sebesar 0,238, uji korelasi berganda hasilnya 0,680, uji t dengan taraf signifikan 0,000 >0,05 dengan nilai kebersihan $t_{\text {hitung }}>t_{\text {tabel }}$ yaitu 2,913 $>2,055$, penerangan $t_{\text {hitung }}>t_{\text {tabel }}$ yaitu 4,343 > 2,055, peralatan produksi thitung $>t_{\text {tabel }}$ yaitu 2,700>2,055, uji $F$ diperoleh $F_{\text {hitung }}>F_{\text {tabel }}$ yaitu 7,465 > 2,980.
\end{abstract}

Kata Kunci : Kebersihan, Penerangan, Peralatan Produksi dan Produktivitas Karyawan

\section{PENDAHULUAN}

\section{Latar Belakang}

Dalam perusahaan, masalah lingkungan kerja dan kenyamanan kerja adalah penting karena dengan lingkungan kerja yang aman, tenang dan tentram, maka orang yang bekerja akan bersemangat dan dapat bekerja secara baik sehingga hasil kerjanya pun memuaskan. Demikian pula dengan masalah kenyamanan kerja, masalah kenyamanan kerja Jurnal Penelitian Ilmu Manajemen yang sangat baik akan membuat karyawan bekerja dengan baik karena para karyawan merasa nyaman dalam menjalankan tugasnya, sebaliknya apabila lingkungan kerja kurang baik misalnya, kebersihan lingkungan kerja yang kurang memadai, penerangan yang kurang baik, serta peralatan produksi yang kurang memadai akan mengakibatkan menurunnya produktivitas kerja karyawan. 
Keselamatan dan Kesehatan Kerja (K3) memang merupakan salah satu persyaratan untuk meningkatkan produktivitas kerja karyawan yang erat kaitannya dengan hasil produksi. Pada dasarnya K3 adalah upaya mencegah atau mengurangi kecelakaan dengan cara meniadakan atau menghilangkan resiko guna mencapai target kerja atau produksi.

Kebersihan lingkungan ialah suatu keadaan yang bebas dari kotoran seperti debu, sampah dan juga bau. Indonesia khususnya, masalah kebersihan lingkungan tersebut selalu menjadi perdebatan dan juga masalah yang terus berkembang. Fasilitas produksi yang dominan didalam pabrik adalah mesin dan peralatan. Peralatan adalah peralatan-peralatan atau perlengkapan-perlengkapan yang dipergunakan oleh perusahaan, baik dikantor maupun ditempat proses produksi dilangsungkan. Perlengkapan atau peralatan tersebut digunakan oleh perusahaan bukan untuk menjalankan proses produksi. Peralatan produksi merupakan media untuk mengolah bahan menjadi produk dengan bantuan pekerja.

Penciptaan lingkungan kerja dan kenyamanan kerja yang baik adalah salah satu bentuk upaya untuk menciptakan tempat kerja yang aman, sehat dan bebas dari pencemaran lingkungan, sehingga dapat mengurangi atau bebas dari kecelakaan kerja dan penyakit akibat Jurnal Penelitian Ilmu Manajemen kerja yang pada akhirnya dapat meningkatkan efisiensi dan produktivitas kerja karyawan. Ruangan kerja akan terlihat sangat menyenangkan dan nyaman apabila seluruh karyawan dan pihak manajemen bisa saling menjaga keutuhan fasilitas yang tersedia dengan cara menjaga kebersihan, memperhatikan penerangan yang sudah ada dan juga merawat peralatan produksi yang tersedia, maka dapat tercipta lingkungan kerja dan kenyamanan kerja yang optimal.

Berdasarkan latar belakang tersebut diatas maka dapat dirumuskan masalah sebagai berikut : Apakah faktor kebersihan, penerangan dan peralatan produksi berpengaruh secara parsial terhadap produktivitas karyawan pada CV Sinar Badja Electric di Surabaya ?, Apakah faktor kebersihan, penerangan dan peralatan produksi berpengaruh secara simultan terhadap produktivitas karyawan pada CV Sinar Badja Electric di Surabaya? dan Faktor manakah diantara faktor kebersihan, faktor penerangan dan faktor peralatan produksi yang paling dominan berpengaruh terhadap produktivitas karyawan pada CV Sinar Badja Electric di Surabaya?.

\section{Kebersihan}

Kebersihan merupakan syarat pertama untuk pegawai-pegawai yang sehat dan pelaksanaannya tidak akan memerlukan banyak ongkos. 
Dalam setiap urusan hendaknya selalu menjaga kebersihan lingkungan, sebab selain mempengaruhi kesehatan juga akan mempengaruhi kesehatan jiwa seseorang.

Menurut Warman (2014:54) Kebersihan dan kerapian tempat kerja adalah faktor utama untuk mempertahankan semangat kerja yang tinggi. Jagalah agar setiap buangan dan sampah selalu dibersihkan. Tugaskanlah orang khusus untuk mengkosongkan wadah buangan jangan sampai menumpuk sehingga menganggu jalannya pekerjaan. Adakanlah peninjauan sewaktu-waktu dan seringkali, agar anggota tahu bahwa anda tidak menghendaki menurunnya standar efisiensi.

Menurut Liang Gie (2016:363) Kebersihan kantor mencakup : Kebersihan Bangunan, semua bagian dari bangunan gedung hendaknya selalu bersih, seperti dinding, lantai, langit-langit, halaman sekitar gedung dan bagian gedung yang lain (kamar mandi dan wc) ; Kebersihan Perlengkapan , Perlengkapan kantor seperti meja, kursi, almari, mesin kantor harus selalu bersih. Jika para karyawan akan bekerja tidak perlu lagi disibukkan dengan perlengkapan kantor yang masih kotor.

Menurut Warman (2014:62) Langkah-langkah yang dapat menunjang kebersihan tempat kerja
:Kebersihan merupakan tanggungjawab seluruh karyawan, melakukan kegiatan pembersihan tempat kerja tiga menit setiap hari, seluruh karyawan adalah petugas kebersihan, bersihkan setiap tempat walaupun jarang digunakan dan biasakan kebersihan merupakan inspeksi awal untuk menemukan kesalahan-kesalahan kecil.

\section{Peneranga}

Menurut Liang Gie (2016:369) Penerangan didalam lingkungan kerja maksudnya adalah cukupnya sinar yang masuk kedalam ruang kerja masing-masing pegawai kantor.

Menurut Siregar (2014:04) Penerangan ialah pencahayaan buatan didalam ruangan tertutup maupun terbuka, yang kuat lemahnya bergantung pada tanggapan mata manusia. Menurut Siregar (2014:93) Ciri-ciri penerangan yang baik yaitu :Sinar/cahaya yang cukup, Sinar/cahaya yang tidak berkilau atau menyilaukan, Terangnya cahaya, Distribusi cahaya, bayangan dan pemancaran/penebaran cahaya.

Menurut Sabir (2013:15) ada 5 sistem penerangan di ruangan :

1. Sistem Penerangan Langsung (direct lighting)

2. Sistem Penerangan Semi Langsung (semi direct lighting)

3. Sistem Penerangan Difus (general diffuse lighting) 
4. Sistem Penerangan Semi

Tidak Langsung (semi indirect lighting)

5. Sistem Penerangan Tidak Langsung (indirect lighting)

\section{Peralatan Produksi}

Menurut Siregar (2014:112) Jenis-jenis mesin dapat dibedakan atas 2 jenis, yaitu : Mesin yang bersifat umum/serbaguna merupakan suatu jenis mesin yang dibuat untuk mengerjakan pekerjaan-pekerjaan tertentu untuk berbagai jenis barang/produk atau bagian dari produk. Contoh: mesin gergaji pada perusahaan pemotongan kayu adalah merupakan mesin yang serbaguna karena dapat digunakan untuk menggergaji berbagai jenis hasilhasil kayu. Mesin yang bersifat khusus adalah mesin-mesin yang direncanakan dan dibuat untuk mengerjakan satu atau beberapa jenis kegiatan yang sama. Contoh: mesin pembuat gula pasir, mesin ini biasanya ditemui pada perusahaanperusahaan yang mengadakan produksi missal.

Menurut Wibowo (2014:6) yang termasuk dalam kelompok peralatan antara lain :

1. Furniture and Fixture / perlengkapan-perlengkapan ruangan yang biasanya terdapat dalam kantor bagian administrasi.

2. Delivery Equipment / kendaraan-kendaraan atau Jurnal Penelitian Ilmu Manajemen

$\begin{aligned} & \text { alat-alat angkutan } \\ & \text { digunakang } \\ & \text { memperlancar jalannya }\end{aligned}$
kegiatan perusahaan.

\section{Produktivitas}

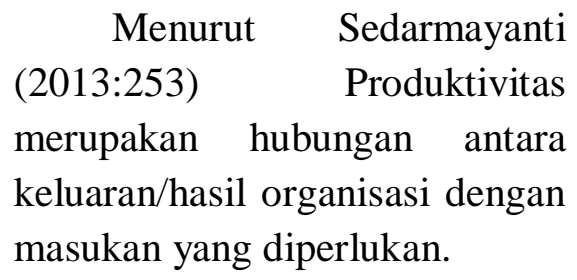

Winardi dalam Kamus Ekonomi yang menyatakan bahwa produktivitas adalah jumlah yang dihasilkan setiap pekerjaan dalam jangka waktu tertentu.

Menurut Sedarmayanti (2013:254) Tipe produktivitas dibagi menjadi 2, yaitu :

1) Total Productivity Ratio

Menghubungkan nilai semua keluaran dengan nilai semua masukan.

2) Partial Productivity Ratio Menghubungkan nilai semua keluaran dengan nilai kategori utama masukan.

\section{METODE PENELITIAN}

Penelitian ini dilakukan untuk mengetahui pengaruh faktor kebersihan, penerangan dan peralatan produksi terhadap produktivitas karyawan pada CV Sinar Badja Electric. Penelitian ini merupakan jenis penelitian 
deskriptif. Variabel bebas X yaitu variabel yang mempengaruhi variabel lain, dalam hal ini variabel bebas adalah Kebersihan, Peneranagan dan Peralatan Produksi. Sedangkan variabel terikat (Y) yaitu variabel yang dipengaruhi oleh variabel lainnya, dalam hal ini yang menjadi variabel terikatnya adalah Produktivitas Karyawan.

Populasi dalam penelitian ini adalah seluruh karyawan CV Sinar Badja Electric yang berjumlah 30 orang. Jenis data yang digunakan dalam penelitian ini adalah Kuantitatif. Data kuantitatif yaitu data yang dapat dinyatakan dalam bentuk angka-angka yang dapat dihitung. Dalam penelitian ini yang termasuk dalam data kuantitatif adalah data jumlah karyawan dan data hasil jawaban kuesioner mengenai kebersihan, penerangan, peralatan produksi dan produktivitas karyawan. Analisis yang digunakan dalam penelitian ini adalah dengan menggunakan analisis uji regresi berganda, uji korelasi berganda, uji t dan uji $F$.

\section{HASIL DAN PEMBAHASAN}

Menurut Usman (2013:232) Analisis regresi linier berganda adalah hubungan antara dua variabel bebas atau lebih yang secara bersama-sama dihubungkan dengan variabel terikatnya.

\section{Tabel 1}

Jurnal Penelitian Ilmu Manajemen
Hasil Regresi Linier Berganda

\begin{tabular}{|l|r|r|}
\hline Variabel & \multicolumn{1}{|c|}{$\begin{array}{c}\text { Koefisien } \\
\text { Regresi }\end{array}$} & $\begin{array}{c}\text { Standar } \\
\text { Error }\end{array}$ \\
\hline $\begin{array}{l}\text { Kebersihan } \\
(X 1)\end{array}$ & $\mathbf{0 , 1 7 9}$ & 0,061 \\
\hline $\begin{array}{l}\text { Penerangan } \\
\text { X2) }\end{array}$ & $\mathbf{0 . 2 3 8}$ & 0,055 \\
\hline $\begin{array}{l}\text { Peralatan } \\
\text { Produksi } \\
(X 3)\end{array}$ & $\mathbf{0 , 1 7 0}$ & 0,063 \\
\hline \multicolumn{2}{|l|}{ Konstanta : 5,792 } \\
\hline
\end{tabular}

Sumber: Diolah dari SPSS 21

Berdasarkan hasil perhitungan regresi berganda pada tabel diatas didapatkan suatu persamaan regresi sebagai berikut :

$\mathrm{Y}=\mathrm{a}+\mathrm{b}_{1} \mathrm{X}_{1}+\mathrm{b}_{2} \mathrm{X}_{2}+\mathrm{b}_{3} \mathrm{X}_{3}$

$\mathrm{Y}=5,792+0,179 \mathrm{X}_{1}+0,238 \mathrm{X}_{2}+0,170 \mathrm{X}_{3}$

Dari hasil bebas (kebersihan, penerangan dan peralatan produksi) diatas bernilai positif, berarti mempunyai arah perubahan yang searah dengan variabel terikat (produktivitas karyawan). Dari koefisien variabel bebas diatas, koefisien regresi yang mempunyai nilai terbesar dibanding dengan koefisien regresi lainnya adalah penerangan. Dengan demikian dapat ditarik kesimpulan bahwa faktor yang paling dominan pengaruhnya terhadap produktivitas karyawan adalah faktor penerangan.

\section{Korelasi Berganda}


Menurut Usman (2013: 236) Korelasi berganda adalah hubungan antara 2 variabel atau lebih yang secara bersama-sama dihubungkan dengan variabel terikatnya (Y).

Tabel 2

\section{Hasil Korelasi Berganda}

\begin{tabular}{|l|l|r|}
\hline Model & R & R Square \\
\hline 1 & $\mathbf{0 , 6 8 0}^{\mathbf{a}}$ & 0,463 \\
\hline
\end{tabular}

Sumber: Diolah dari SPSS 21

Dari tabel diatas diketahui bahwa korelasi berganda (R) sebesar 0,680. Sedangkan kontribusi atau sumbangan secara simultan terhadap produktivitas karyawan sebesar 0.463 berarti bahwa variabel kebersihan (X1), penerangan (X2) dan peralatan produksi (X3). Dari nilai $\mathrm{R}$ tersebut dapat ditarik kesimpulan bahwa hubungan antara kebersihan, penerangan dan peralatan produksi secara bersamasama dengan hasil produktivitas karyawan adalah positif dan kuat/tinggi.

\section{Uji t}

Menurut Ghozali (2013:98) Uji t pada dasarnya menunjukkan variabel bebas secara individu mempunyai pengaruh signifikan terhadap variabel terikat.

a. Kebersihan (X1)

Dari hasil uji t diperoleh nilai $t_{\text {hitung }}>t_{\text {tabel }}$ yaitu $2,913>$ 2,055 dengan tingkat signifikan 0,000 > 0,05. Maka
H1 diterima, artinya bahwa ada pengaruh yang signifikan antara kebersihan (X1) dengan produktivitas karyawan (Y).

b. Penerangan (X2)

Dari hasil uji t diperoleh nilai $t_{\text {hitung }}>t_{\text {tabel }}$ yaitu 4,343> 2,055 dengan tingkat signifikan 0,000 >0,05. Maka $\mathrm{H} 2$ diterima, artinya bahwa ada pengaruh yang signifikan antara penerangan (X2) dengan produktivitas karyawan (Y).

c. Peralatan Produksi (X3)

Dari hasil uji t diperoleh nilai $t_{\text {hitung }}>t_{\text {tabel }}$ yaitu $2,700>$ 2,055 dengan tingkat signifikan 0,000 > 0,05. Maka H3 diterima, artinya bahwa ada pengaruh yang signifikan antara peralatan produksi (X3) dengan produktivitas karyawan (Y).

\section{Uji F}

Menurut Ghozali (2013:98) Uji F pada dasarnya menunjukkan apakah semua variabel bebas (independent) mempunyai pengaruh secara bersama-sama terhadap variabel terikat (dependent).

Dari hasil uji $\mathrm{F}$ diperoleh nilai $F_{\text {hitung }}>F_{\text {tabel }}$ yaitu $7,465>2,980$. Maka H4 diterima, artinya bahwa variabel bebas yang terdiri atas Kebersihan (X1), Penerangan (X2) dan Peralatan Produksi (X3) 
mempunyai pengaruh yang simultan terhadap Produktivitas Karyawan (Y).

\section{PENUTUP}

\section{Kesimpulan}

Berdasarkan hasil analisis data yang telah dilakukan terhadap seluruh data yang diperoleh, maka dapat diambil kesimpulan sebagai berikut :

1. Persamaan regresi yaitu : $\mathrm{Y}=5,792+0,179 \mathrm{X}_{1}+$ $0,238 X_{2}+0,170 X_{3}$. Faktor yang paling dominan diantara faktor kebersihan, penerangan dan peralatan produksi adalah faktor penerangan sebesar 0,238 .

2. Kebersihan, Penerangan dan Peralatan Produksi secara parsial berpengaruh positif terhadap Produktivitas Karyawan. Hal ini dibuktikan tingkat signifikan $0,000>0,05$ dengan nilai kebersihan $t_{\text {hitung }}>\mathrm{t}_{\text {tabel }}$ yaitu $2,913>2,055$, Penerangan $t_{\text {hitung }}>\mathrm{t}_{\text {tabel }}$ yaitu $4,343>$ 2,055, Peralatan Produksi $t_{\text {hitung }}>t_{\text {tabel }}$ yaitu $2,700>$ 2,055 .

3. Kebersihan, Penerangan dan Peralatan Produksi memiliki pengaruh secara simultan yang signifikan terhadap Produktivitas Karyawan. Hal ini dibuktikan dengan nilai Jurnal Penelitian Ilmu Manajemen
$F_{\text {hitung }}>F_{\text {tabel }}$ yaitu $7,465>$ 2,980 .

\section{Saran}

Setelah penulis mempelajari keadaan yang terjadi dilingkungan CV Sinar Badja Electric di Surabaya, maka penulis akan mengemukakan saran yang kiranya dapat bermanfaat bagi perusahaan antara lain yaitu :

1. Diharapkan untuk dapat meningkatkan dan menjaga kebersihan di lingkungan $\mathrm{CV}$ Sinar Badja Electric sehingga nantinya karyawan merasa nyaman dan akan melakukan aktivitas produksi dengan semangat.

2. Diharapkan para karyawan CV Sinar Badja Electric di Surabaya dapat menjaga kebersihan dilingkungan kerja, memelihara penerangan di tempat kerja dan juga lebih peka terhadap lingkungan agar dapat tercipta lingkungan kerja yang berkualitas.

3. Kebijakan dan peraturan yang telah dibuat oleh pihak perusahaan hendaknya dipatuhi dan dilaksanakan secara optimal dan berkelanjutan.

\section{DAFTAR PUSTAKA}


Ghozali. 2013. Statistik Menggunakan. Yogyakarta : Andi

Gie, The Liang. 2016. Administrasi Perkantoran. Yogyakarta : Modern Liberty

Sabir, Prabu. 2013. Sistem dan Standar Pencahayaan Ruangan. Yogyakarta : Graha Ilmu

Sedarmayanti, 2013. Membangun dan Mengembangkan Kepemimpinan Serta Meningkatkan Kinerja Untuk Meraih Keberhasilan.

Bandung: PT. Refika Aditama

Siregar, Syofian. 2014. Metode Penelitian Kuantitatif. Jakarta: Kencana Prenadamedia Group

Warman, John. 2014. Manajemen Pergudangan. Cetakan Kelima. Jakarta: CV. Muliasari 